\title{
EDITORIAL: PROBLEM BASED LEARNING: A WAY FORWARD FOR THE MODERN TIMES
}

\author{
Urban John Arnold D'Souza* \\ Professor \& Head of the Department, Faculty of Medicine \& Health Sciences, Universiti \\ Malaysia Sabah, 88400 Kota Kinabalu, Sabah, Malaysia. \\ *Corresponding Author Email: dsouza@ums.edu.my
}

This is an open access article distributed under the Creative Commons Attribution License, which permits unrestricted use, distribution, and reproduction in any medium, provided the original work is properly cited.

\section{ARTICLE DETAILS}

Article History:

Received 12 November 2017 Accepted 12 December 2017 Available online 1 January 2018

\section{ABSTRACT}

Over the years teaching and learning has shifted from teacher centered towards student centered learning. Internet and smart tools in addition has provided a progressive user-friendly platform for learning and gaining knowledge. Passive ways of learning no more are valid and student facilitation rather than teaching is the norm. Problem based learning is a tailored learning culture where the students are at the centre stage. Student's design their objectives for learning and in a step-wise manner solve the problems and gain much deeper learning. It is interactive, student centered and teacher facilitated. Along with subject knowledge it prepares a student with the soft skills which are essential for future career in the industries in which they deliver their services. Problem based learning is future for the new generation as the entire educational system is changing with the availability of smart tools and internet. This shall prepare the younger generation for the industrial revolution -4 and surely lead towards a progressive and realtime learning culture.

\section{KEYWORDS}

Problem based learning, student-centered, active learning.

\section{INTRODUCTION}

Teaching-learning are the two faces of same coin though in modern times, teaching need to be replaced by facilitating as the technological innovations internet and digital world has eased the way for information. Age-old teacher centred learning seems to be slowly moving to the back stage as modern day and future need to be upgraded to meet the demand of the world market. Around four decades back, Maastricht University with McMaster, stepped forward to bring a change in education, especially in learning strategy by introducing Problem Based Learning [1]. It is a new approach wherein every student is task masters revolving around a problem and teacher is a facilitator in the learning culture. Olden days educational system was more of a passive way of learning, where auditory learning was primary, and the student shall be listening attentively for the information delivered by a teacher. Moreover, a set of learning principles and theories were delivered to the student. But the future society and modern times have changed with technological inventions and challenges are the norms. So also, the passive learning, if not shifted to the challenge based learning, future generation may be at a cross road. In problem based learning student will be learning towards a problem with a challenging atmosphere. The real problems are dealt in a stepwise manner which are meaningful problems based on the curriculum. These problems are aptly selected for the students' future professional practices.

PBL method has confirmed a correlation in educational and clinical performance of students which were practiced in medical schools [2]. Usually, a problem learning session involves; meaningful relevant problems around the curriculum, formation of small groups as a small group of 8-10 participants makes a good interactive team. Thirdly, a tutor/teacher who acts as a facilitator is also one among the learning team. Tutor does not take a center-stage; rather he facilitates the entire flow of the learning. He makes sure that, each and every member of the learning team is active and only facilitate the learning towards the goals that to be achieved. Lastly, it makes sure that, every member of the learning group makes lot of self-study, may be at home, hostels, libraries to enable the timely discussions with new information to share with.
Along the course of this learning group, lot of new information is pooled, each member has to challenge and seek a tendency of sharing their knowledge with an interaction. In this PBL a student has to gain knowledge that is relevant to the problem and this knowledge is gained along the different sessions and acquiring this knowledge can be still comparable to the olden traditional teaching with the exception of teacher deciphering the knowledge than the student, himself proactively finding the resources actively and learning the required background. In the learning environment acquired knowledge need to be actively discussed among the group, while the tutor facilitates the right direction for the learning. In the learning session, every member keeps appreciating each other for the contribution and the new knowledge that brought in for discussions. This enables the students to learn the important soft skills, communication, patience, tolerance, collaboration which prepares them for their future profession.

In a nutshell, problem based learning include four basic spices or ingredients namely; active participation, constructive theory based learning or contextual learning where students are able to understand and construct meaning for their learning. Thirdly, every member in the team is encouraged for a self-directed learning as the objectives or learning issues in the problem based learning directs them for a meaningful self-directed learning. Lastly, and most importantly, interactive and collaborative learning that enables a deeper understanding of the subject of focus. In a traditional learning, the sessions are more towards a passive learning where the teacher is active, and the student is a listener. Teacher tries to deliver information and the listeners, partly accumulates the knowledge for temporary duration and the information stored is lost in few minutes to hours. In Problem Based Learning, since the student is active, he finds himself the resources and prepares for acquiring knowledge, meanwhile interacts, explains their understanding, collaborates and asks questions in the group. While learning the group member may contradict, listen; share the information and knowledge which enable him for a self-directed learning. Solving the problems is an active mental activity, that enhances the knowledge enabling new skills that shall be retained and comprehensively make the learner to understand deeply [3] 
Problem based learning is a way forward for the present time as future professions are mostly task oriented, instead of service providing, they move towards innovative with application of technology, digitalization, and internet based. Many Universities around the World has already adopted problem based learning in their curricula be it arts, law, science, medicine and engineering. PBL has positive effect in academia and an effective and relevant method with relevant cognitive advantage [4].

\section{REFERENCES}

[1] Servant, V.F., Schmidt, H.G. 2016. Revisiting Foundations of problembased learning: some explanatory notes. Medical Education, 50 (7), 698701.
[2] Lucas, K.H., Testman, J.A., Hoyland, M.N., Kimble, A.M., Euler, M.L. 2013. Correlation between active-learning coursework and student retention of core content during advanced pharmacy practice experiences. American Journal of Pharmaceutical Education, 77 (8), 171.

[3] Yuan, H., Kunaviktikul, W., Klunklin, A., Williams, B.A. 2008. Improvement of nursing students' critical thinking skills through problembased learning in the People's Republic of China: A quasiexperimental study. Nursing and Health Sciences, 10 (1), 70-76.

[4] Sayyah, M., Shirbandi, K., Malehi, A.S., Rahim, F. 2017. Use of a problem-based learning teaching model for undergraduate medical and nursing education: a systematic review and meta-analysis. Advances in Medical Education and Practice, 8 (2), 691-700. 